Vol 10, Issue 10, 2017

\title{
EFFICACY OF SIMPLE BLEACH DIGESTION OF SPUTUM IN THE DIAGNOSIS OF PULMONARY TUBERCULOSIS BY MICROSCOPIC EXAMINATION
}

\author{
GRACE CORRINE KHONG YIN LEONG, LEESHA SHARON*, POOJA PANDEY, NADEEM GULDAR, \\ GOPALKRISHNA BHAT K
}

Department of Microbiology, Kasturba Medical College, A Constituent College of Manipal University, Mangalore, Karnataka, India. Email: sharon.leesha@gmail.com

Received: 09 May 2017, Revised and Accepted: 30 June 2017

ABSTRACT

Objective: Rapid diagnosis of pulmonary tuberculosis (PTB) depends on microscopic examination of sputum smear for acid-fast bacilli (AFB). The direct microscopy examination lacks sensitivity. It needs at least 10,000 AFB/ml of sputum to observe in the smear. The objective of this study was to determine the efficacy of three different short-term bleach digestions and concentration of sputum in the diagnosis of PTB.

Methods: A total of 171 sputum samples collected from patients suspected of having pulmonary TB were used. Direct smear was prepared using each sample and then divided into three parts to which equal volume of $5 \%$ bleach was added. The first part was kept at room temperature for 45 minutes with intermittent shaking. The second part was allowed to stand at room temperature for 45 minutes for sedimentation, and the third part was kept at room temperature for 45 minutes and then centrifuged at $3000 \mathrm{~g}$ for 15 minutes for deposit formation. Smears were prepared and stained with Ziehl-Neelsen method and observed for AFB using Revised National TB Control Programme Guidelines.

Results: Out of 171 sputum samples, 45 (26.32\%), 48 (28.07\%), 49 (28.65\%), and 55 (32.16\%) of specimens were positive by direct, bleach digested mixed method, bleach digested sedimented method, and centrifugation method, respectively. The background of the bleach digested sputum smears was clear.

Conclusion: Short-term bleach digestion of sputum improves the sensitivity of microscopic examination and the number of AFB observed in the smear. Bleach being a disinfectant kills AFB and makes handling of sputum safer.

Keywords: Microscopy, Bleach digestion, Pulmonary tuberculosis.

(C) 2017 The Authors. Published by Innovare Academic Sciences Pvt Ltd. This is an open access article under the CC BY license (http://creativecommons. org/licenses/by/4. 0/) DOI: http://dx.doi.org/10.22159/ajpcr.2017.v10i10.19786

\section{INTRODUCTION}

Tuberculosis (TB) is a serious public health problem in many parts of the world. Globally out of 8.6 million TB cases, 2.2 million were estimated to have occurred in India [1]. TB causes more adult deaths than any other single infectious disease. TB affects the productive age group of 15-54 years, which in turn affects their economic burden during the sickness [2]. Human immunodeficiency virus infection increases the risk of reactivation TB to about $10 \%$ per year [3].

Microscopic examination of sputum smear for acid-fast bacilli (AFB) is still the cornerstone of TB diagnosis in the developing world $[4,5]$. Since microscopy is useful in the detection of infectious cases, it is an important component of TB control program [6]. However, the sensitivity of direct microscopy is low, ranging $30-40 \%$ with single specimen to $65-75 \%$ with repeated sputum samples [7]. Uneven distribution of AFB in sputum may affect the results of microscopic examination. Various concentration methods have been studied to increase the chance of finding AFB in sputum smears $[8,9]$. These methods need digestion and centrifugation at 3000-3800 g to concentrate AFB [10]. Such high-speed centrifuges may not be available in many laboratories. Different workers employed concentration methods such as centrifugation and sedimentation using different concentrations of bleach to evaluate bleach microscopy method [11]. Bleach has bactericidal activity which may help in potentially protecting the staff from TB infection during processing [12]. Further, concentration of sputum increases the workload of the laboratory. Therefore, a simple, cost-effective method of sputum microscopy can be very useful in diagnosing TB. The purpose of this study was to determine the efficacy of three different short-term bleach digestions and concentration of sputum in the diagnosis of pulmonary $\mathrm{TB}$.

\section{METHODS}

This study was conducted using 171 sputum samples collected from patients suspected to have pulmonary TB. This study was conducted in the Department of Microbiology of a private Medical college in Coastal Karnataka, India. This study had approval of Institutional Ethics Committee. Each sputum sample was used for direct smear and bleach digestion as per algorithm in Fig. 1.

\section{Direct smear}

The purulent part of the sputum was taken with the help of a bacteriological loop, and the smear was prepared on new slide.

\section{Short-term bleach digestion of sputum}

The bleach digestion was carried out using a previously described method with some modifications [13]. Each sputum sample was divided equally into three parts. The bleach powder manufactured by the NICE Chemicals (P) Ltd., India, was dissolved in distilled water to make $5 \%(\mathrm{w} / \mathrm{v})$ solution.

\section{Bleach digested mixed simple}

An equal amount of $5 \%(\mathrm{w} / \mathrm{v})$ bleach was added to the sputum samples, mixed well and kept at room temperature $\left(25^{\circ} \mathrm{C}\right)$ for 45 minutes with intermittent shaking. Finally, the digested sample was once again mixed; a drop was placed on a slide and allowed to dry. Then, the smear was heat fixed and stained with Ziehl-Neelsen (ZN) method. The smear was observed for AFB using oil immersion objective. 


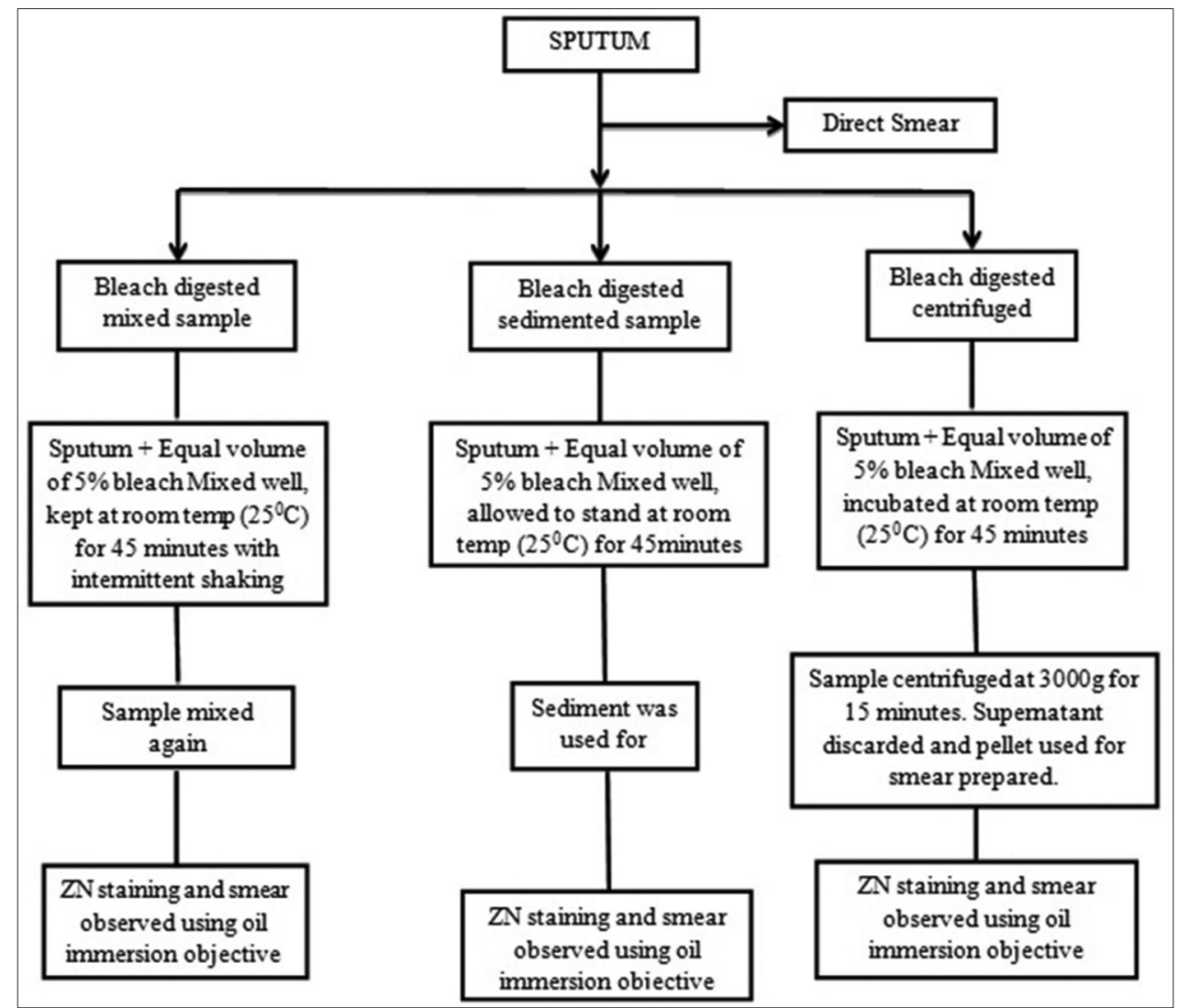

Fig. 1: The processing of sputum by three different methods of bleach digestion

\section{Bleach digested sedimented sample}

An equal volume of $5 \%$ bleach was added to the sputum samples, mixed well and allowed to stand at room temperature $\left(25^{\circ} \mathrm{C}\right)$ for 45 minutes. A drop of the sediment was placed on a slide and a smear was prepared. The smear was air dried, heat fixed and stained by ZN method and observed for AFB using oil immersion objective.

Bleach digested centrifuged sample

An equal volume of $5 \%$ bleach was added to the sputum samples, mixed well and incubated at room temperature $\left(25^{\circ} \mathrm{C}\right)$ for 45 minutes. The bleach digested sample was centrifuged at $3000 \mathrm{~g}$ for 15 minutes. The supernatant was discarded and the pellet was used for smear preparation. The smears were stained using ZN method and observed for AFB using oil immersion objective.

Observation and grading of sputum smear for AFB

A minimum of 100 oil immersion fields were observed for AFB and grading was done using Revised National TB Control Programme Guidelines. Table 1 comparison was made between results obtained with the direct and three types of bleach digested ZN smears. Smear positive pulmonary TB (PTB) cases were diagnosed by demonstration of AFB in at least two sputum samples.

\section{RESULTS}

We studied 171 sputum samples collected from patients suspected to have pulmonary TB. Out of these, $45(26.32 \%)$ were positive by direct ZN method, 48 (28.07\%) by bleach digestion and mixing, 49 (28.65\%) by bleach digestion and sedimentation, and 55 (32.16\%) samples were positive when bleach digested sample was centrifuged at $3000 \mathrm{~g}$ for 15 minutes, and the centrifuged deposit was used for ZN staining (Table 2).

The results clearly indicate that bleach digestion of sputum increased the sensitivity of detection of AFB in the smear. However, the difference was not statistically significant. The background of bleach digested
Table 1: Revised National TB Control Programme Guidelines for grading AFB in sputum smear

\begin{tabular}{ll}
\hline Number of bacilli & Result/grade \\
\hline No AFB/100 OIF & 0 \\
$1-9$ AFB $/ 100$ OIF & Scanty \\
10-99 AFB/100 OIF & Positive 1+ \\
$1-10$ AFB/OIF & Positive 2+ \\
>10 AFB/OIF & Positive 3+ \\
\hline
\end{tabular}

OIF: Oil immersion fields, AFB: Acid-fast bacilli

Table 2: Comparison of direct and bleach digested sputum sample smear for the demonstration of AFB

\begin{tabular}{|c|c|c|c|}
\hline \multirow[t]{2}{*}{ Method } & \multicolumn{2}{|c|}{ Number of specimens (\%) } & \multirow[t]{2}{*}{ Total } \\
\hline & Positive & Negative & \\
\hline Direct & $45(26.32)$ & $126(73.68)$ & 171 \\
\hline $\begin{array}{l}\text { Bleach digested mixed } \\
\text { specimen }\end{array}$ & $48(28.0)$ & $123(71.93)$ & 171 \\
\hline $\begin{array}{l}\text { Bleach digested sedimented } \\
\text { specimen }\end{array}$ & 49 (28.65) & $122(71.35)$ & 171 \\
\hline $\begin{array}{l}\text { Bleach digested centrifuged } \\
\text { sample }\end{array}$ & $55(32.16)$ & $116(67.84)$ & 171 \\
\hline
\end{tabular}

AFB: Acid-fast bacilli

sputum smear was clear. Further, we observed that the number of bacilli found in the bleach digested smear was more compared to the direct smear (Table 3).

\section{DISCUSSION}

Diagnosis of PTB worldwide is to a large extent dependent on direct microscopy of sputum smears after ZN staining. Microscopy is rapid 
Table 3: Effect of bleach digestion and concentration of sputum on grading of smear

\begin{tabular}{|c|c|c|c|c|c|}
\hline \multicolumn{6}{|l|}{ Method } \\
\hline Number of positive samples & $3+$ & $2+$ & $1+$ & Scanty & Total \\
\hline Direct smear & 10 & 21 & 10 & 4 & 45 \\
\hline $\begin{array}{l}\text { Bleach digested mixed sputum } \\
\text { smear }\end{array}$ & 12 & 22 & 12 & 2 & 48 \\
\hline $\begin{array}{l}\text { Bleach digested sedimented } \\
\text { sputum smear }\end{array}$ & 13 & 23 & 12 & 1 & 49 \\
\hline $\begin{array}{l}\text { Bleach digested centrifuged } \\
\text { deposit smear }\end{array}$ & 20 & 29 & 5 & 1 & 55 \\
\hline
\end{tabular}

and reasonably easy to perform. Further, it helps to identify the infectious patients. The WHO Directly Observed Therapy Short Course programme relies on the microscopic examination of sputum for tubercle bacilli. However, the sensitivity of smears made directly from sputum is low [14], and there is a strong case for using rapid, reliable and nonexpensive procedures which will improve the accuracy of the diagnosis of pulmonary TB in countries with low economic status. Mycobacterial culture is regarded as the gold standard but it is slow and cumbersome to be used in routine laboratories in resource poor settings. Many concentration methods have been studied with different success rate $[9,15,16]$. We chose to evaluate the short-term bleach digestion of sputum because of its low cost and simplicity.

In this study, we evaluated bleach digested mixed specimen, bleach digested sedimented specimen, and bleach digested centrifuged specimen for the detection of AFB. In all these procedures, $5 \%(\mathrm{w} / \mathrm{v})$ bleach solution was used for digestion of the sputum samples. All these three methods improved the sensitivity of the microscopy for the detection of AFB as compared to direct smear. The bleach digested mixed specimen could detect AFB in 48 specimens, whereas the bleach digested sedimented specimen in 49 samples and the highest sensitivity was achieved by the bleach digested centrifuged specimen (55 out of 171 samples). The increased sensitivity of bleach digested specimen is probably due to greater concentration of AFB and removal of debris by the bleach. Bleach is effective in digestion of the sputum, thus, lowering the viscosity of the sample thereby accelerating the rate of setting. We observed that bleach digested specimen provided clear field definition under the microscope. Digestion of sputum with $5 \%$ bleach for 45 minutes resulted in easy detection of tubercle bacilli against clear background. The literature search did not reveal any previous study on simple bleach digestion followed by mixing in the diagnosis of TB.

The rate of settling $\mathrm{r}(\mathrm{cm} / \mathrm{s})$ of spherical particles is calculated by Stoke's law.

$$
r=\frac{2 a 2 g(d p-d m)}{9 n}
$$

Where, $\mathrm{a}=$ radius of particle $(9 \mathrm{~cm}), \mathrm{g}=$ acceleration due to gravity, $\mathrm{dp}=$ density of the particle, $\mathrm{dm}=$ density of medium, $\mathrm{n}=$ viscosity of the medium (gs units).

It is clear that the rate of settling can be increased by either increasing the gravitational force or decreasing the viscosity of the medium. The gravitational force is increased artificially in the centrifuge and is measured by the relative centrifugal force. AFB requires a high centrifugal force of at least $3000 \mathrm{~g}$ for 15 minutes for settling. Such special centrifuges may not be available in many routine laboratories. The relative centrifugal force achieved in an ordinary centrifuge is grossly inadequate to concentrate AFB.

Handling sputum samples poses a risk of infection due to live Mycobacterium TB present in the sample. Bleach disinfects the samples thereby lowering the risks of laboratory acquired infections. This is especially useful and important for developing countries where adequate safety cabinets may not be available for processing sputum samples.

Short-term bleach digestion of sputum has many advantages. First, sensitivity is better compared to direct microscopy. Second, the technique is safe, inexpensive and easy to perform. Further, bleach is readily available. Third, as a potent disinfectant, bleach kills MTB and thus eliminates the risk of laboratory infections. Fourth, being strongly alkaline, bleach dissolves mucous and frees the tubercle bacilli. Fifth, bleach reduces debris in sputum and gives clear field definition under the microscope.

The bleach digestion of sputum for laboratory diagnosis of pulmonary TB has certain disadvantages also. First, bleach treated sample cannot be used for culture. Second, bleach method requires more time than direct method.

Short-term bleach digestion of sputum improves the sensitivity of microscopy examination and improves the number of AFB observed in the smear. Further, bleach being a disinfectant may kill AFB and make handling of sputum safer. The laboratories which depend only on smear examination for diagnosis of pulmonary TB can use this short-term bleach digestion of sputum to improve the diagnosis of TB.

\section{ACKNOWLEDGMENT}

The authors thank Indian Council of Medical Research, New Delhi, India, for supporting this research under short-term studentship. The authors thank Manipal University for logistic support.

\section{REFERENCES}

1. TB India 2014 Revised National TB Control Programme Annual Status Report. Available from: http://www.tbcindia.nic.in/documents

2. Sajith M, Thomas A, Kothia JJ, Chandrakar B, Pawar A, Bargaje MD. Cost of therapy incurred for tuberculosis patients receiving directly observed therapy (DOTS). Int J Pharm Pharm Sci 2015;7(10):141-4.

3. Saranya P, Swathi S, Kousalya K, Praveen D. A prospective interventional study of knowledge, attitude and practice (KAP) towards tuberculosis among patients with Koch's disease. Int J Pharm Pharm Sci 2016;8(3):58-61.

4. Gebre N, Karlsson U, Jönsson G, Macaden R, Wolde A, Assefa A, et al. Improved microscopical diagnosis of pulmonary tuberculosis in developing countries. Trans R Soc Trop Med Hyg 1995;89(2):191-3.

5. Lawson L, Yassin MA, Ramsay A, Olajide I, Thacher TD, Davies PD, et al. Microbiological validation of smear microscopy after sputum digestion with bleach; A step closer to a one-stop diagnosis of pulmonary tuberculosis. Tuberculosis (Edinb) 2006;86(1):34-40.

6. World Health Organisation. Guidelines for National Programmes. WHO/Tb/97.220. Geneva: WHO; 1997.

7. Daniel TM. Rapid diagnosis of tuberculosis: Laboratory techniques applicable in developing coutries. Rev Infect Dis 1989;11 Suppl 2:S471-8.

8. Kant L. Improving detection of infectious cases. Indian $\mathrm{J}$ Tuberc 2001;48(3):115-6

9. Bruchfeld J, Aderaye G, Palme IB, Bjorvatn B, Källenius G, Lindquist L. Sputum concentration improves diagnosis of tuberculosis in a setting with a high prevalence of HIV. Trans R Soc Trop Med Hyg 2000;94(6):677-80.

10. Bhat KG. Value of sputum concentration in the diagnosis of pulmonary tuberculosis. Trans R Soc Trop Med Hyg 1999;93(1):107-8.

11. Ameh J, Shuaibu UA, Aminu I, Henry M, Humphrey M, Kingsley O, et al. Improving the case detection of pulmonary tuberculosis by bleach microscopy method in the North West of Nigeria. J Med Lab Diagn 2013;43:34-7.

12. Chew R, Calderón C, Schumacher SG, Sherman JM, Caviedes L, Fuentes $\mathrm{P}$, et al. Evaluation of bleach-sedimentation for sterilising and concentrating Mycobacterium tuberculosis in sputum specimens. BMC Infect Dis 2011;11:269.

13. World Health Organisation. Laboratory Services in Tuberculosis Control. Parts I-III WHO/Tuberculosis/98.258. Geneva: WHO; 1998.

14. Van DA, Maug A, Cooreman E, Hossain MA, Chambuganj N, Rema $\mathrm{V}$, et al. Bleach sedimentation method for increased sensitivity 
of sputum smear microscopy: Does it work? Int J Tuberc Lung Dis 2000;4(4):371-6

15. Aung WW, Nyein MM, Ti T, Maung W. Improved method of direct microscopy for detection of acid-fast bacilli in sputum. Southeast Asian
J Trop Med Public Health 2001;32(2):390-3

16. Angeby KA, Alvardo-Galvez C, Pineda-Garcia L, Hoffner SE. Improved sputum smear microscopy for a more sensitive diagnosis of pulmonary tuberculosis. Int J Tuberc Lung Dis 2000;4:684-7. 